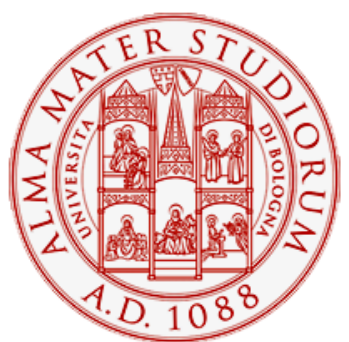

Alma Mater Studiorum - Università di Bologna DEPARTMENT OF ECONOMICS

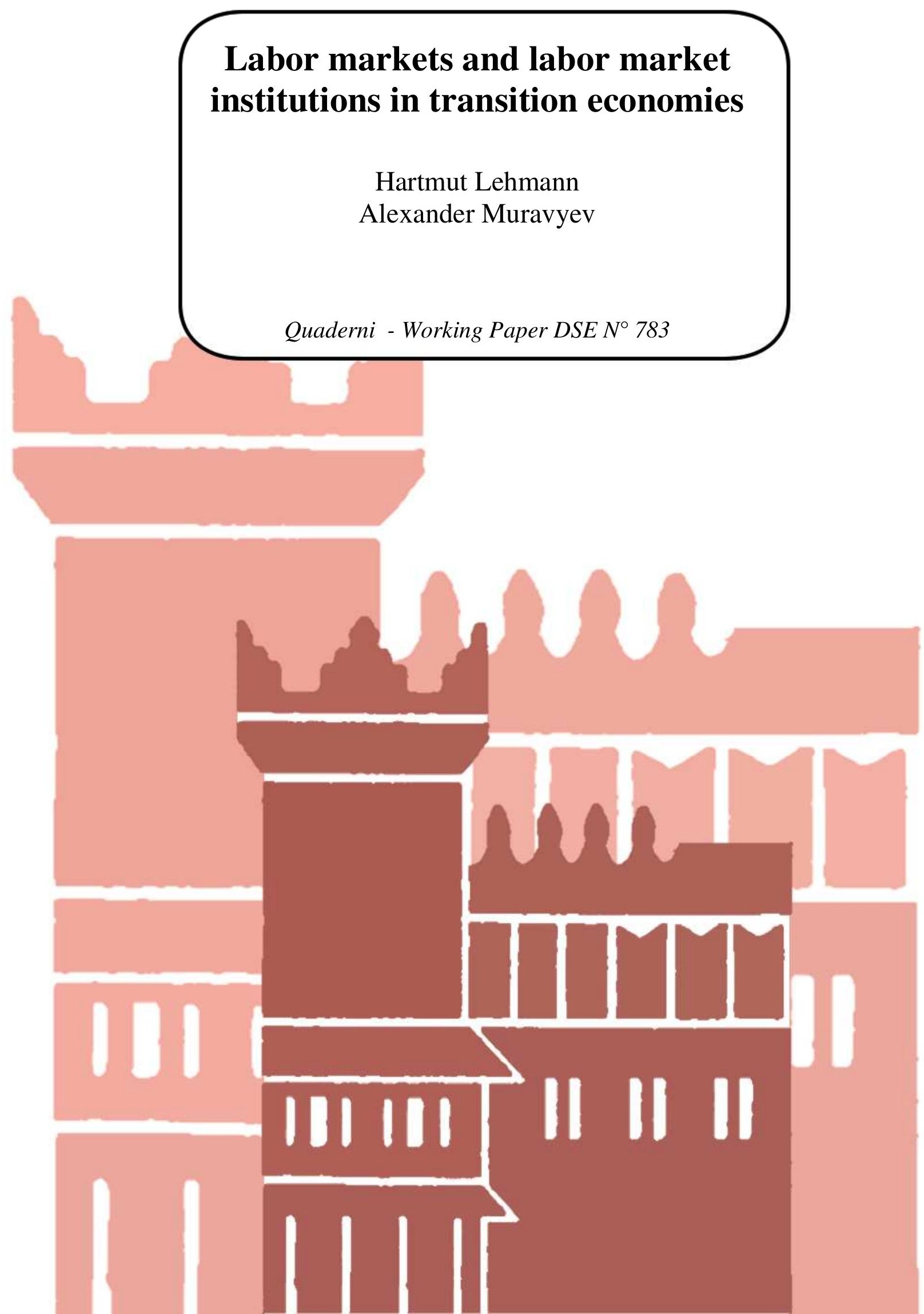




\title{
Labor markets and labor market institutions in transition economies*
}

\author{
Hartmut Lehmann** (University of Bologna and IZA) \\ Alexander Muravyev (IZA and St. Petersburg University GSOM)
}

\begin{abstract}
This paper summarizes the evolution of labor markets and labor market institutions and policies in the countries of Central and Eastern Europe as well as of Central Asia over the last two decades. The main focus is on the evolution of labor market institutions, which are among candidate explanations for the very diverse trajectories of labor markets in the region. We consider recent contributions that attempt to assess the effect of labor market institutions on labor market performance of TEs, including the policy-relevant issue of complementarity of institutions.
\end{abstract}

Keywords: labor markets, unemployment, labor market institutions, transition economies. JEL codes: J21, P20.

\footnotetext{
*This paper has been prepared for the Routledge Handbook on "The Economics and Political Economy of Transition”, edited by Paul Hare and Gerard Turley and due for release in 2012. We thank the editors for useful comments and suggestions.

We are also grateful to the Volkswagen Foundation for financial support within the project "The Political Economy of Labor Market Reform in Transition Countries: A Comparative Perspective.”
}

\footnotetext{
${ }^{* *}$ Corresponding author: hartmut.lehmann@unibo.it
} 


\section{Introduction}

This paper is on the evolution of labor markets and labor market institutions and policies in the countries of Central and Eastern Europe as well as of Central Asia over the last two decades. As the dynamics of labor market outcomes in these transition economies (TEs) has drawn considerable attention already in the early years of transition and resulted in a voluminous literature easily available elsewhere, the paper provides only a sketchy summary of the topic. Instead, we focus on the much less explored issue of the evolution of labor market institutions, which are among candidate explanations for the very diverse trajectories of labor markets in the region. We consider recent contributions that attempt to assess the effect of labor market institutions on labor market performance of TEs, including the policyrelevant issue of complementarity of institutions.

\section{Labor Market Dynamics}

The transition from plan to market, which countries of Central and Eastern Europe as well as of Central Asia (transition economies, TEs) embarked in the late 1980s-early 1990s, implied profound changes in their labor markets. Until the late 1980s, most of these economies, apart from Yugoslavia, were characterized by large excess labor demand, no open unemployment, and high labor force participation. For example, estimates of the actual unemployment in the USSR show numbers of the order of 1 to 2 percent and the available statistics on employment show employment ratios among those aged $15-59$ being as high as 83.6 percent in the late 1980s. These very high employment rates and close to zero open unemployment came, however, at a price as extremely low labor productivity and substantial labor hoarding were pervasive features of the centrally planned economy (Granick, 1987).

The start of the transition saw a rapidly collapsing demand for labor. In part, it was a consequence of the inefficient use of labor resources during the central planning period, 
which became apparent once market forces were released in TEs. More importantly, it reflected the collapse of output that TEs were facing in the late 1980s and early 1990s. Indeed, from the start of transition in 1989 until the resumption of economic growth, these countries lost from between one-fifth and more than two-thirds of their pre-transition level of GDP (EBRD, 2000). Figure 1 illustrates this pattern. For presentational purposes, we distinguish between Central European economies $(\mathrm{CEE})^{1}$, South Eastern European economies $(\mathrm{SEE})^{2}$, and the Commonwealth of Independent States (CIS) ${ }^{3}$, and compare them with the EU-15 and the US. Figure 1 shows a relatively modest and short decline in GDP in CEE occurring in the early 1990s and a much deeper and longer recession in CIS. SEE countries stand out as the region impacted by the conflict in the former Yugoslavia. Overall, at the end of the 1990s, robust economic growth came back to all the regions and remained until the 2008 financial crisis. During this period, TEs were growing faster than both the EU-15 and the US.

How did the labor markets of TEs respond to these dramatic changes in GDP? In general, the adjustment of the labor markets following the initial transition shock occurred via falling employment rates, rising unemployment, reductions in working hours, and decreasing real wages - the whole gamut of the available adjustment mechanisms. However, these different mechanisms played out with different intensity in the various transition regions (Svejnar, 1999). In particular, during the early transition, CEE experienced falling employment rates and growing unemployment, accompanied by a modest decline in real wages. The former Soviet Union instead saw collapsing real wages with relatively limited

\footnotetext{
${ }^{1}$ The Czech Republic, Estonia, Hungary, Latvia, Lithuania, Poland, the Slovak Republic, and Slovenia.

${ }^{2}$ Albania, Bosnia and Herzegovina, Bulgaria, Croatia, Macedonia, Montenegro, Romania, and Serbia.

${ }^{3}$ Until recently, the CIS included 12 out of 15 constituent republics of the former USSR, namely Armenia, Azerbaijan, Belarus, Georgia, Kazakhstan, Kyrgyzstan, Moldova, Russian Federation, Ukraine, Tajikistan, Turkmenistan, and Uzbekistan, with Georgia officially leaving the organization in August 2009.
} 
rises in at least, official rates, of unemployment and falls in employment (Boeri and Terrell, 2002). ${ }^{4}$ Figures 2 and 3 provide some support for this point. Despite a much more dramatic decline in GDP, employment in CIS fell less than in CEE while the unemployment rate remained lower than in CEE until the late 1990s. SEE experienced a large decline in employment and high unemployment, but this was largely due to the wars in the former Yugoslavia since the unemployment and employment dynamics in Bulgaria and Romania, not affected by the conflict, are quite similar to that in CEE.

Interestingly, the resumption of economic growth in CEE in the mid-1990s was not accompanied by increasing employment and falling unemployment. For example, Poland and Slovakia, while growing fast, experienced large declines in employment and increases in unemployment, which approached $20 \%$ in the early 2000 s. Only since then has there been a steady increase in the employment rate and a decline in the unemployment rate in CEE. CIS countries, which grew very fast between the late 1990s and 2008, did not, on average, see any increases in employment. It mostly remained flat (Kyrgyzstan, Russia, Ukraine) or even declined (Armenia, Georgia, Moldova) despite the robust economic growth in the region. The unemployment rate in CIS nevertheless saw some decline after its peak in the late 1990s. As for SEE, some upturn in employment occurred in the mid-2000s, albeit it remains rather low and unemployment very high in the region (except for Bulgaria and Romania).

Presented at the level of the three large country groups, the data suggest considerable heterogeneity in the evolution of labor markets in transition countries over the last two decades. The differences are even larger if one avoids aggregation and examines separate countries. The countries of CIS then appear by far the most diverse in terms of economic development and labor market dynamics, with increasing heterogeneity in the most recent

\footnotetext{
${ }^{4}$ Non-standard mechanisms of labour market adjustment became widespread in CIS in the 1990s. These included wage arrears, forced leaves, reduction in working hours and in-kind payments in lieu of cash wages (Lehmann, Wadsworth and Acquisti, 1999; Earle and Sabirianova, 2002).
} 
years. On one side of the spectrum, there are resource-rich countries like Russia and Kazakhstan with modest, single-digit unemployment rates and a high employment rate (above 70\%). On the other side there are low-income countries like Armenia and Tajikistan, with higher unemployment and a very low employment rate (below 50\% as of 2009). Indeed, the recent data provide some support to the view expressed in Rutkowski and Scarpetta (2005) that a divide is emerging between labor markets of high- and upper middle-income European transition countries, particularly in CEE, and of low-income countries, especially those of Central Asia:

'Labor markets in European transition economies in many respects resemble those in developed economies of Europe, in both positive (for example, productivity growth) and negative aspects (for example, high and stagnant unemployment). In contrast, labor markets in low-income CIS countries seem to become similar to those in other low-income countries, with typical characteristics such as the dominant informal sector, underemployment, and low productivity employment.'

\section{Labor Market Institutions and Policies}

The diverse and often unconventional patterns of labor market adjustment in TEs have caused scholars and policy-makers to look for institutional explanations of these different labor market outcomes.

The set of labor market institutions that TEs had at the beginning of transition was rather atypical of mature market economies, but has changed considerably over the last 20 years. In the late 1980s, workers still felt well protected from unemployment in most parts of the region, but the protection stemmed from excess demand for labor, rather than from institutions such as employment protection legislation, an active role of trade unions 
regarding workers' rights, or unemployment benefits. ${ }^{5}$ In fact, many of such labor market institutions and policies were simply missing. It was not until the late $1980 \mathrm{~s}$ when, against the background of looming unemployment, TEs engaged in an active development of specific institutions and policies in order to ensure an effective functioning of labor markets. Two decades after the start of the transition process, most countries have established sets of labor market institutions and policies, similar to those existing in mature market economies.

Below we focus on the evolution of key labor market institutions and policies in transition countries over the last two decades and compare them with the respective institutions and policies in the EU-15 and the US. Similarly to studies of OECD economies, the focus is on employment protection legislation (EPL), union density, coverage and bargaining, the tax wedge on labor, the duration of unemployment benefits, the average replacement ratio and expenditures on active labor market policies (ALMP).

\subsection{Employment protection legislation}

There is some debate in the literature concerning the evolution of employment protection in TEs over the two last decades. To a large extent, the debate stems from the lack of a commonly agreed measure of employment protection, which reflects the general difficulty of measuring institutions. ${ }^{6}$ Some sources suggest that during the early transition period, employment protection in many countries, especially those of CIS and SEE, was quite tough, reflecting socialist legacies. These rigid regulations were subsequently liberalized over the course of transition, albeit to different degrees in different countries. However, a new study by one of the authors of this contribution suggests a more nuanced picture. For the case of the

\footnotetext{
${ }^{5}$ With respect to open unemployment, the former Yugoslavia seems to be the only important exception. For example, Macedonia suffered from double-digit unemployment rates as early as the late 1970s.

${ }^{6}$ The most known indicators of employment protection are the OECD EPL indicator and the 'Employing workers' index from the Doing Business database.
} 
ex-USSR states, Muravyev (2010) shows that essential rigidities to national labor laws, such as restrictions on the use of fixed-term contracts and large severance payments, were not inherited from the Soviet time, but were rather introduced in the late 1980s-early 1990s, at the early stage of transition, when governments attempted to combat looming unemployment. The evolution of labor regulations thus followed an inverted U-shaped pattern with the peak of rigidity occurring in the 1990 s.

Most sources nevertheless suggest liberalization of labor laws in TEs in the last decade, often quite dramatic as in the case of Georgia and Kazakhstan (Muravyev, 2010). As a result, most transition countries are in the middle of the labor market flexibility scale, at least as judged by the existing estimates based on the OECD EPL methodology (OECD, 2009). ${ }^{7}$ Panel 1 of Figure 4 illustrates these dynamics for the three regions. The data show considerable declines in EPL in SEE and especially CIS between 1995 and 2007, although not in CEE. Overall, TEs as a group now appear to be quite similar to EU-15. Still, in terms of EPL, of all TEs only Georgia is close to the US, which has one of the most liberal sets of labor market laws in the world.

\subsection{Union density, coverage and bargaining}

Although trade unions (with almost universal membership) existed already at the time of the planned economy, in most countries (with the notable exception of Poland) they were de facto an integral part of the Communist party and state apparatus, transmitting policy directives to the workforce (Borisov and Clarke, 2006). It is fair to say that TEs did not have a system of industrial relations typical of mature market economies and such a system was only gradually taking shape during the first decade of transition. Perhaps the clearest

\footnotetext{
${ }^{7}$ This is especially true if an assessment of the rigidity of labour laws takes into account the issue of law enforcement, which is quite lax in many countries, especially in the former USSR (see Gimpelson et al., 2010; Rutkowski and Scarpetta, 2005).
} 
manifestation of this development is the decline of unionization rates to the levels observed in mature market economies. Panel 2 of Figure 4 illustrates this development.

Overall, CEE countries have achieved a more visible progress in establishing a system of industrial relations typical of Western democracies. For example, the effectiveness of trade unions in promoting the economic interests of their members increased already in the 1990s, although some scholars argue that even in CEE, industrial relations can be considered still in a process of flux.

The picture emerging in CIS can be illustrated by looking at Russia. According to formal criteria, by the mid-1990s the country had an established system of industrial relations, characterized by a high unionization rate, multi-level collective bargaining, a high coverage rate, and a very high degree of coordination among both employees and employers (Cazes, 2002). More recent and more careful examinations of the country's industrial relations system, however, have revealed that many of the institutions created in the 1990s remained more like a form without content. In particular, decisions of the tripartite commission have no legislative status under Russian law and are therefore not binding; general agreements usually contain many purely declarative provisions, and violations of these agreements are typically left without sanctions (Borisov and Clarke, 2006). It is nearly impossible to define and classify wage coordination mechanisms in the Central Asian transition countries.

\subsection{The tax wedge on labor}

The early transition period was characterized by relatively high taxation of labor, especially in the form of high payroll taxes. By the early 1990s, TEs had progressive personal income taxes, although the highest marginal rates were generally below those in EU-15. A number of reforms, aimed at reducing the tax wedge on labor, which can be thought of as the difference 
between take home pay and the labor cost to the employer, were introduced since then. The most notable reform was the introduction of flat personal income taxes in most TEs, following the pioneering example of Estonia in 1994. However, the tax burden on labor has remained rather high in Central Europe, though not in most of the other transition countries. This can be seen in Panel 3 of Figure 4. Indeed, despite some reduction between 1999 and 2007, the tax wedge on labor in CEE is just a little below that in EU-15. In contrast, SEE and in particular the CIS have managed to reduce the tax wedge considerably. It is also noteworthy that the tax wedge is far lower in the US than in the other four regions.

\subsection{Unemployment benefits}

At the start of transition, even if substantial unemployment rates were foreseen, the governments, especially in Central Europe, adopted fairly generous unemployment benefits schemes mainly out of political considerations. ${ }^{8}$ These were subject to cuts, sometimes dramatic, in the 1990s as the governments struggled to keep budget discipline in the face of a considerable and largely unanticipated decline in output. These cuts concerned both the unemployment insurance replacement rates and the maximum potential duration of unemployment benefit payments.

Panels 5 and 6 of Figure 4 show benefit durations and the average replacement rates. CEE and SEE have maximum durations of roughly one year, whereas the CIS exhibits the shortest durations in the transition region. Compared to the EU-15 and the US, replacement rates are not very generous in CEE and the CIS, while SEE has somewhat higher rates. The EU-15, in contrast, combines long maximum duration with relatively generous

\footnotetext{
${ }^{8}$ For example, in Poland the strong political position of 'Solidarity' allowed the Mazowiecki government in December 1989 to introduce layoffs in labour legislation only in tandem with the introduction of a very generous unemployment benefit system that in its first, albeit shortlived, version did grant open-ended benefits to anybody, even if the person had no previous work experience.
} 
unemployment benefit levels, while the US has the shortest maximum duration of benefits combined, however, with a relatively high replacement rate.

\subsection{Active labor market policies}

While active labor market programs have been introduced throughout the region, their share in GDP has been lower than in the old member states of the EU and substantially lower in South-Eastern Europe and the former Soviet Union. The EU-15 on average spends roughly 1 percent of GDP on ALMP, while all transition regions spend far less (Lehmann and Kluve, 2010). Especially in the CIS, governments spend very little on such policies.

\subsection{Minimum wages}

Non-trivial minimum wages existed in some countries before the start of the transition process. For example, in the USSR, the ratio of minimum to average wage (the Kaitz index) was about $38 \%$ in 1985 . In the 1990 s, there was a remarkable erosion of minimum wages in CIS countries, with the Kaitz index falling below $10 \%$ in some countries. In contrast, the level of minimum wages in CEE countries has been maintained at a much higher level. In the early 2000 s, CEE and SEE had minimum wages around $40 \%$ of the average wage.

\section{Institutions as Determinants of Labor Market Performance}

The evidence on how labor market institutions and policies have affected labor market outcomes in Eastern Europe and Central Asia is scarce. This is mainly caused by data constraints, especially regarding the early stages of the transition process. For example, it was only in the early 2000s when the first cross-country data on the stringency of labor regulations in the region appeared. In general, the quality of data is better in the new member states of the EU, and declines southwards and especially eastwards. The countries of Central 
Asia have by far the worst availability of data on labor market performance and labor market institutions.

As a result, most of the existing studies of labor market institutions in transition countries are based on data from the new member states and/or adopt a partial approach by focusing on particular institutions and policies, often within a particular country. A major problem of many studies that focus on specific institutions is thus that they do not allow for general equilibrium effects and interactions between institutions, a key issue in the modern literature on the institutional determinants of labor market performance. There is only a handful of cross-country studies that attempt to analyze the role of labor market institutions, including Cazes and Nesporova (2003), Fialova and Schneider (2009), as well as Lehmann and Muravyev (2010) which rely on standard linear regression models as in, e.g., Nickell (1997). Of these studies, most use data from OECD or EU-15 countries augmented with data from a handful of transition countries (typically, the Czech Republic, Hungary, Poland and Slovakia); to date, Lehmann and Muravyev (2010) remains the only study that provides a comprehensive analysis of over 20 TEs, which also looks at interactions between different institutions and policies. We, therefore, focus on the results of this work, drawing on other evidence when appropriate.

\subsection{The impact of institutions on labor market performance in isolation}

We organize our discussion of the impact of labor market institutions on labor market outcomes around Table 1, which gives a non-technical summary of the empirical evidence presented in the study by Lehmann and Muravyev. Important insights are gained by looking at several measures of labor market performance, in this special case, at the employment rate, the unemployment, long-term unemployment and youth unemployment rates. 
Panel 1 of Table 1 shows which institutions impact on the four measures of labor market performance when each institution is looked at individually. EPL has a very strong negative impact on the employment rate and a strong positive effect on the youth unemployment rate. So, on average, stricter employment protection legislation seems to reduce the employment rate in transition countries and increase youth unemployment. This result is in line with theoretical considerations: stricter EPL protects incumbent workers but firms are reluctant to hire new labor market entrants, thus possibly depressing overall employment and increasing youth unemployment. The empirical evidence on the impact of EPL presented before our study was based on more limited data with respect to the set of transition countries and to time, and is also rather contradictory and inconclusive and thus not very useful in buttressing the validity of the results shown in the first row of panel 1.

Increasing expenditures on ALMP only seems to lower the youth unemployment rate according to the second row of panel 1 . This is not that surprising given how little transition countries spend on these policies and given that many governments, especially in CEE and SEE, have tried to fight the high incidence of youth unemployment by concentrating expenditures on this group of the unemployed. Overall unemployment and long-term unemployment do not seem affected by ALMP. ${ }^{9}$ These general equilibrium results that are achieved with data covering most TEs and most of the transition period are corroborated, at least in part, by the microeconometric and macroeconometric evaluation literature on ALMP in transition countries summarized in Lehmann and Kluve (2010). For ALMP measures to work at the individual level, careful targeting is required; in addition, there seems to exist a hierarchy of measures with respect to their effectiveness: job brokerage and retraining and further training seem particularly promising in that they increase the average likelihood of a

9 Lehmann and Muravyev (2010) do find negative effects of ALMP on overall unemployment and long-term unemployment. However, given the small number of observations used in their macroeconomic regressions these effects are not significant at conventional levels. 
participant to find regular employment. Wage and job subsidies applied in TEs produce mixed results, while public works are nearly unanimously considered detrimental to a participant's chances to gain regular employment because of stigmatization or benefit churning mechanisms. The general equilibrium effects in individual countries produced by earlier macroeconometric work, on the other hand, are rather inconclusive since, e.g., in a low unemployment country, like the Czech Republic in the 1990s, researchers have found increased outflows from unemployment caused by increased expenditures on ALMP, while an insignificant impact was found in Poland where unemployment has been notoriously high throughout the transition period.

The third significant determinant of labor market performance is the tax wedge on labor. As we can see in the third row of panel 1, an increase in labor taxation will lower the employment rate but will not affect the unemployment measures. This is in line with previous empirical evidence insofar as all previous studies that focused on TEs unambiguously hint at the detrimental effect of high taxation on labor market performance. However, in some studies increasing the tax wedge raises unemployment, in others it lowers employment and participation levels. When one looks at the average impact of the tax wedge across most TEs as is done in our study, the demand for labor seems to be the most important channel through which the tax wedge operates, since the employment rate will be strongly co-determined by labor demand while the three types of unemployment should be driven predominantly by labor supply decisions.

The fourth institution that has some impact on labor market performance in TEs is union density. Countries where more workers are enrolled as members of a trade union have on average a lower employment rate. Some corroborating, albeit relatively weak, evidence can be found in Ederveen and Thissen (2007) who show that higher union density increases unemployment. Unfortunately it was impossible to find data on collective bargaining for all 
TEs. Studies that analyze the impact of collective bargaining on labor market performance for a subset of transition countries in general find a positive impact.

The last two institutions shown in panel 1, the duration of unemployment benefits and their level, do not have any effect with respect to all four measures of labor market performance. This result is very much in line with earlier evidence as Commander and Heitmueller (2007) as well as Ederveen and Thissen (2007) find no effect of the duration and generosity of unemployment benefits on unemployment. The apparently weaker link between unemployment benefit systems and labor market performance if compared to OECD countries can be explained, at least in part, by the low job creation capacity of most transition countries over most of the transition period. In other words, labor supply mechanisms are relatively unimportant when analyzing outflows from unemployment as has been well demonstrated for example in the case of Hungary by Micklewright and Nagy (2010). ${ }^{10}$ Analyzing the impact of institutions on labor market performance in isolation, three of the six institutions and policies, namely EPL, tax wedge and ALMP seem to be of particular policy relevance implying, e.g., in the case of the tax wedge and EPL, that the liberalizing agenda promoted by the Bretton Woods institutions has some merit. ${ }^{11}$

\subsection{The complementary nature of labor market institutions and policies}

\footnotetext{
${ }^{10}$ The design of unemployment benefit systems, very different when we compare CEE and the CIS, had an important impact on labour market performance at the beginning of the transition, though (Boeri and Terrell, 2002). Relatively generous benefits in CEE created a wage floor that made labour costly, leading to large layoffs, which resulted in a rapid rise of unemployment. At the same time it caused a high reservation wage implying a 'stagnant' unemployment pool. In the CIS, having not very generous benefit provisions, no such wage floor existed, resulting in wage adjustment rather than employment adjustment. A more moderate rise in unemployment and larger outflows from unemployment were the consequences according to Boeri and Terrell.

${ }^{11}$ We do not discuss the effect of minimum wages on labour market performance, since there are no cross-country studies covering the majority of TEs that allow any generalizing inferences.
} 
We finish our analysis by looking at what happens when institutions interact with each other. Some researchers suggest that institutions and policies interact in a systematic fashion and thus act in a complementary way when reforms of several institutions are tackled simultaneously. Complementarity can be explained with a classic example shown in Nickell (1997), discussing the level of unemployment benefits. Ceteris paribus, a high level of unemployment benefits should imply a higher unemployment rate, but when interacted with a short duration of these benefits and large expenditures on ALMP, generous unemployment benefits might result in better labor market performance. For OECD countries, several studies have pointed at this complementary interaction of institutions. ${ }^{12}$ Lehmann and Murvayev (2010) is to date the only study which looks at the issue of reform complementarities in transition countries. They augment the baseline regression equation such as in Nickell (1997) with pairwise interactions of labor market institutions and policies for the full sample of transition countries. Their results are briefly discussed here.

Raising expenditures on ALMP will have a stronger impact on unemployment and long-term unemployment if the labor market is characterized by a relatively low tax wedge (row 1 of panel 2). This result is intuitively quite plausible. If, e.g., an ALMP measure targeted at the long-term unemployed is meant to rebuild their human capital, such a measure will result in larger outflows into employment if labor is taxed less. A similar argument can be made with the interaction of ALMP and EPL. ALMP measures are meant to make the unemployed fit for unsubsidized regular employment. If EPL is relatively unregulated, firms will be more willing to hire from the unemployment pool, a result that is shown in row 5 of panel 2. The complementary effect of lowering the tax wedge and shortening benefit duration also seems to us rather convincing. According to row 12 of panel 2, this complementarity will boost outflows from long-term and youth unemployment. It is these results that are

\footnotetext{
${ }^{12}$ One such study is Bassanini and Duval (2009).
} 
particularly interesting from a policy point of view as they imply that broad reform packages that tackle more than one institution or policy will result in better labor market performance than reforming only one institution at a time.

\section{Conclusions}

The above analysis documents considerable heterogeneity in the evolution of labor markets in TEs over the last two decades, especially at the level of separate countries. The countries of the CIS appear by far the most diverse in terms of economic development and labor market dynamics, with increasing divergence in the most recent years.

The set of labor market institutions that TEs had at the beginning of transition was rather atypical of mature market economies, but has changed considerably over the last two decades. There has been considerable liberalization of labor regulations in TEs, more pronounced than in the old EU member states. By now, most TEs have established sets of labor market institutions and policies, which are similar to those existing in mature market economies.

A growing literature suggests the importance of labor market institutions in the determination of labor market outcomes in TEs. This is particularly true of EPL, the tax wedge and ALMP. Overall, data from TEs suggest that deregulation of labor markets improves their performance. There is also substantial evidence from TEs that reforming two institutions jointly or applying broad reform packages will generate larger benefits than a partial reform focusing on a single labor market institution.

This brief review leaves untouched several important issues that might have strong impacts on labor market dynamics in TEs. This is particularly true of inter-country (undocumented) migration and informal employment, which have apparently been more pronounced in transition than in OECD countries. The evidence on these phenomena in TEs 
remains scarce; it is still to be seen how they interact with and shape labor markets in transition countries. 


\section{References}

Bassanini, Andrea and Romain Duval (2009) Unemployment, Institutions, and Reform

Complementarities: Re-assessing the Aggregate Evidence for OECD Countries, Oxford Review of Economic Policy 25(1): 40-59.

Boeri, Tito and Katherine Terrell (2002) Institutional Determinants of Labor Reallocation in Transition, Journal of Economic Perspectives 16(1): 51-76.

Borisov, Vadim and Simon Clarke (2006) The Rise and Fall of Social Partnership in Postsocialist Europe: the Commonwealth of Independent States. Industrial Relations Journal 37(6): 607-629.

Cazes, Sandrine (2002) Do Labor Market Institutions Matter in Transition Economies? An Analysis of Labor Market Flexibility in the Late Nineties. Discussion Paper 140/2002, International Institute for Labor Studies, ILO.

Cazes, Sandrine and Alena Nesporova (2003) Labor Markets in Transition: Balancing Flexibility and Security in Central and Eastern Europe. Geneva, ILO.

Commander, Simon and Axel Heitmueller (2007) Does Unemployment Insurance Help Explain Unemployment in Transition Countries? Unpublished paper, London Business School.

Earle, John S. and Klara Z. Sabirianova (2002) How Late to Pay? Understanding Wage Arrears in Russia, Journal of Labor Economics 20(3): 661-660.

EBRD (2000) Transition report. EBRD, London.

Ederveen, Sjef and Laura Thissen (2007) Can Labor Market Institutions Explain High Unemployment Rates in the New EU Member States? Empirica 34(4): 299-317.

Fialova, Kamila and Ondřej Schneider (2009) Labor Market Institutions and Their Effect on Labor Market Performance in the New EU Member Countries. Eastern European Economics 47(3): $57-83$. 
Gimpelson, Vladimir, Rostislav Kapeliushnikov, and Anna Lukyanova (2010) Employment Protection Legislation in Russia: Regional Enforcement and Labor Market Outcomes.

Comparative Economic Studies 52(4): 611-636.

Granick, David (1987) Job Rights in the Soviet Union: Their Consequences, Cambridge: Cambridge University Press.

Lehmann, Hartmut and Alexander Muravyev (2010) Labor Market Institutions and Labor Market Performance: What can we Learn from Transition Countries? Working Paper 714, Dipartimento Scienze Economiche, Universita' di Bologna.

Lehmann, Hartmut and Johen Kluve (2010) Assessing Active Labor Market Policies in Transition Countries, in Floro, E.C. and F. Pastore (eds.), The Labor Market Impact of EU Enlargement: A New Regional Geography for Europe? Heidelberg, Physica-Verlag, 275-308. Lehmann, Hartmut, Wadsworth, Jonathan and Alessandro Acquisti (1999) Grime and Punishment: Job Insecurity and Wage Arrears in the Russian Federation, Journal of Comparative Economics 27(4): 595-617.

Micklewright, J. and G. Nagy (2010) The Effect of Monitoring Unemployment Insurance Recipients on Unemployment Duration: Evidence from a Field Experiment', Labor Economics 17(1), 180-187.

Muravyev, Alexander (2010) Evolution of Employment Protection Legislation in the USSR, CIS and Baltic States, 1985-2009, IZA Discussion Paper 5365.

Nickell, Stephen (1997) Unemployment and Labor Market Rigidities: Europe versus North America. Journal of Economic Perspectives 11(3): 55-74.

Rutkowski, Jan J. and Stefano Scarpetta (2005) Enhancing Job Opportunities: Eastern Europe and the Former Soviet Union. World Bank, Washington DC. 
Svejnar, Jan (1999) Labor Markets in the Transitional Central and Eastern European Economies. In O. Ashenfelter and D. Card (eds.) Handbook of Labor Economics. New York and Oxford, Elsevier Science, North-Holland, 3(3): 2809-857. 
Figure 1. GDP dynamics in transition countries, EU-15, and US

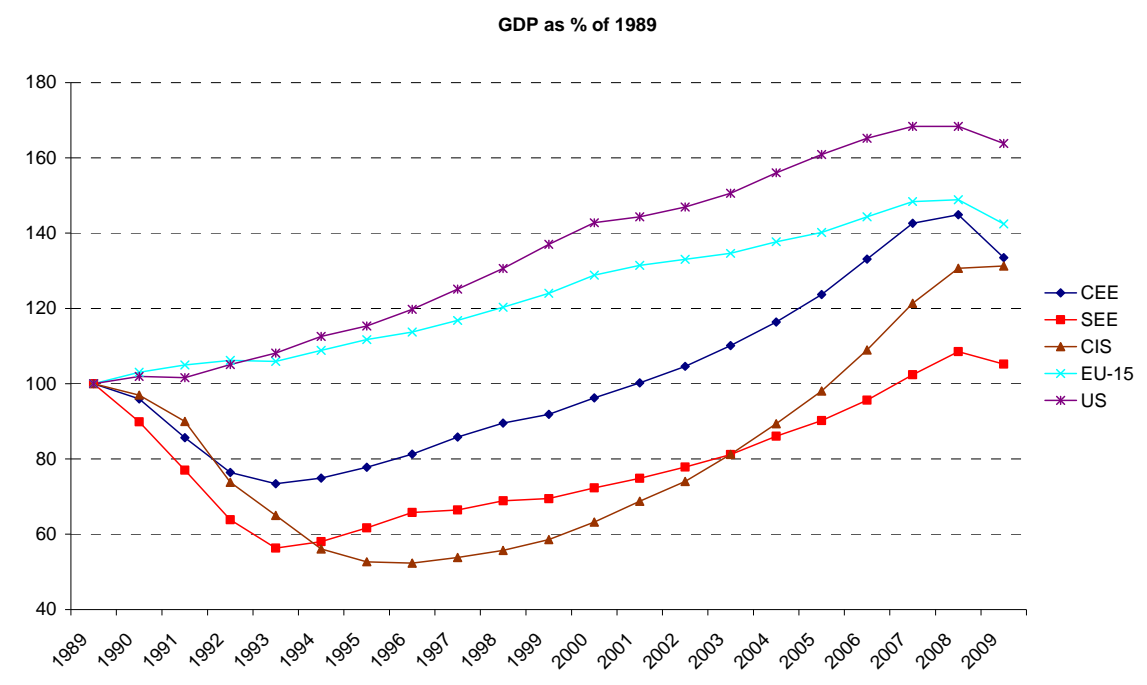

Notes: Unweighted averages for TEs and EU-15. The data come from EBRD and OECD databases.

Figure 2. Employment-to-population ratios in transition countries, EU-15, and US.

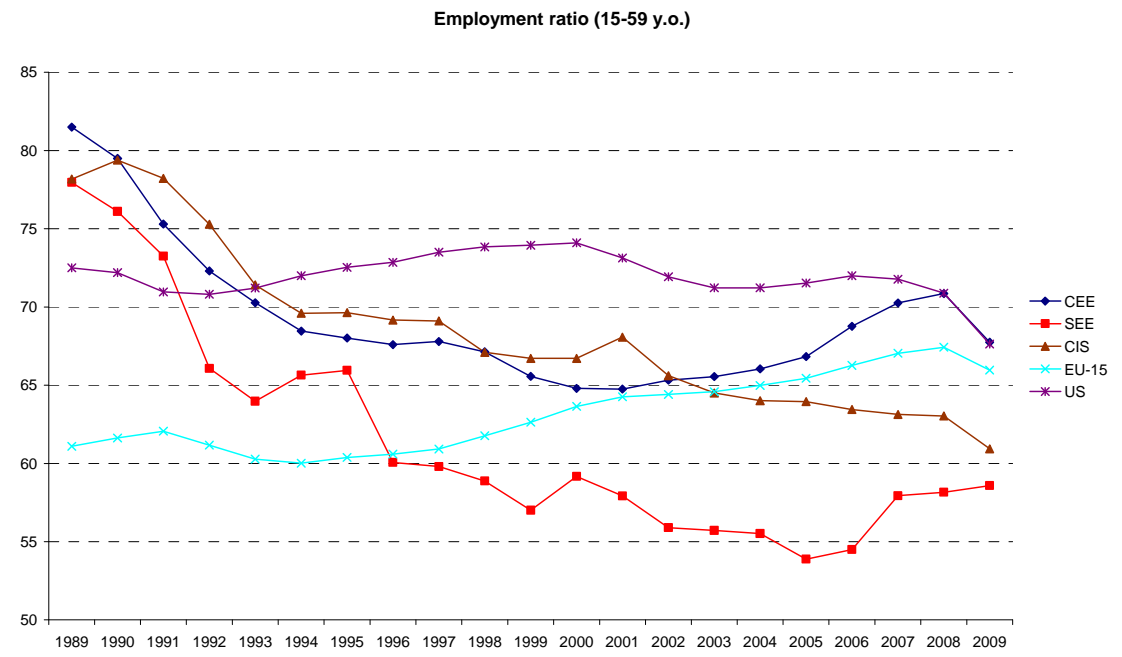

Notes: 15-64 for EU-15 and 16-64 for US. Unweighted averages for TEs and EU-15. The data are from TRANSMONEE and OECD databases. 
Figure 3. Unemployment rates in transition countries, EU-15, and US.

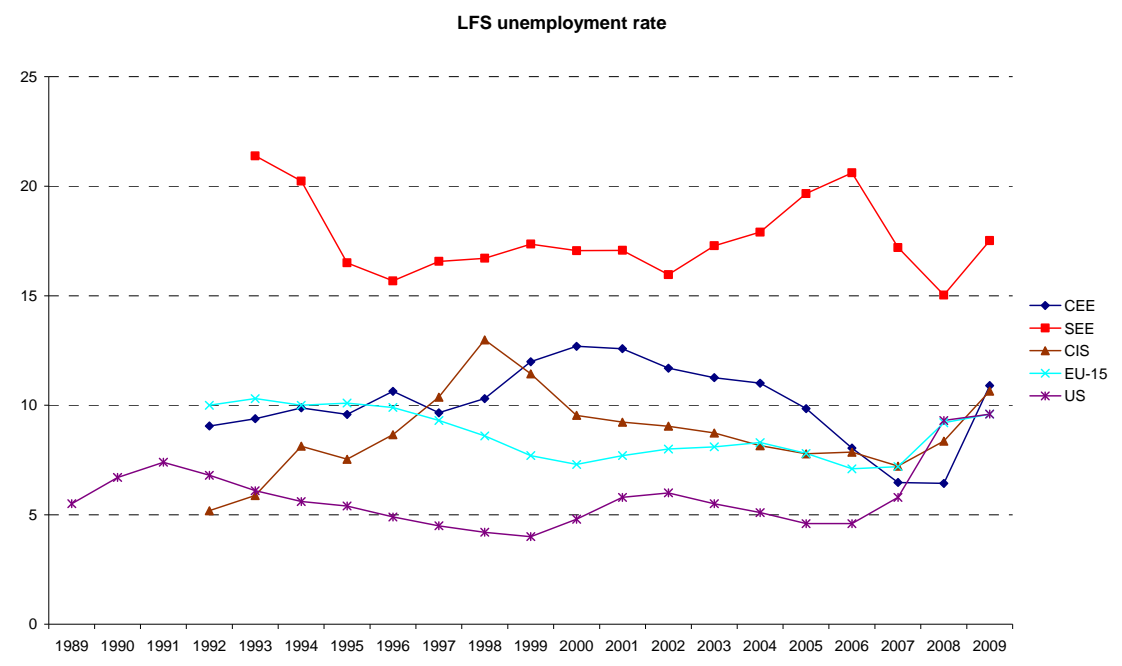

Notes: Unweighted averages for TEs and EU-15. The data are from TRANSMONEE and OECD databases. 
Figure 4. Labor market institutions by region (1995 to 2007)
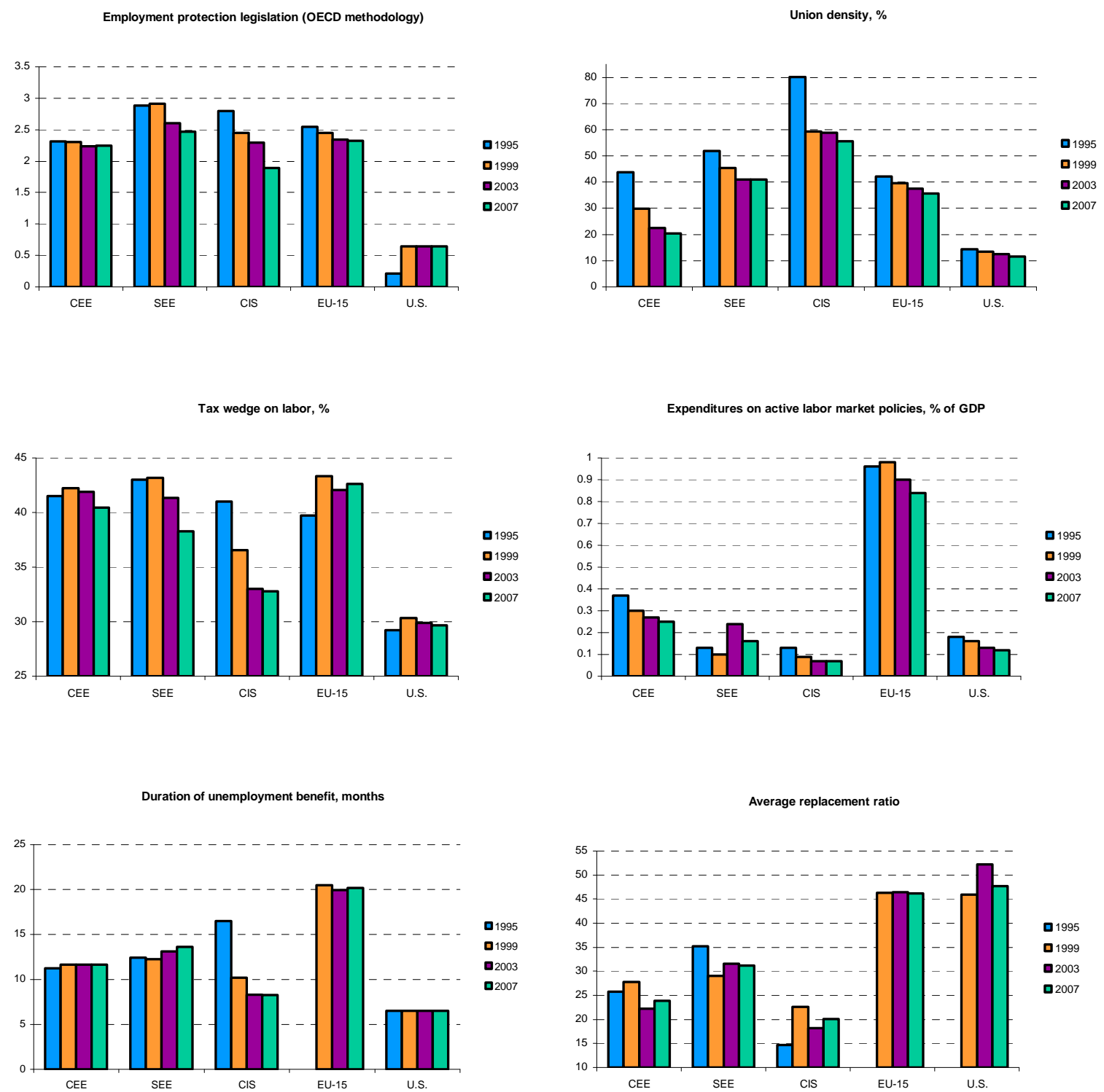

Source: Lehmann and Muravyev (2010). 
Table 1. Institutions and labor market outcomes (Lehmann and Muravyev 2010).

Panel 1. Baseline results.

\begin{tabular}{|c|c|}
\hline $\begin{array}{l}\text { Employment } \\
\text { ate }\end{array}$ & $\begin{array}{l}\text { Unemployment } \\
\text { rate }\end{array}$ \\
\hline
\end{tabular}

\begin{tabular}{lcllc}
\hline EPL & --- & 0 & 0 & ++ \\
ALMP & 0 & 0 & 0 & --- \\
TAX & - & 0 & 0 & 0 \\
DENS & - & 0 & 0 & 0 \\
BEND & 0 & 0 & 0 & 0 \\
BENF & 0 & 0 & 0 & 0 \\
\hline \hline
\end{tabular}

Note: -, -- and ---: negative impact and significant at the $10 \%$, the $5 \%$ and the $1 \%$ significance levels; ++: positive impact and significant at the 5\% significance level.

Panel 2. Interactions between institutions and their complementarity

\begin{tabular}{|c|c|c|c|c|}
\hline & $\begin{array}{l}\text { Employment } \\
\text { rate }\end{array}$ & $\begin{array}{l}\text { Unemployment } \\
\text { rate }\end{array}$ & $\begin{array}{l}\text { Long-term } \\
\text { unempl. rate }\end{array}$ & $\begin{array}{l}\text { Youth unempl. } \\
\text { rate }\end{array}$ \\
\hline$\overline{\mathrm{ALMP} \text { TAX }}$ & 0 & Comp** & Comp** & 0 \\
\hline ALMP_DENS & 0 & Comp** & Comp* & Comp** \\
\hline ALMP_BENF & 0 & 0 & 0 & 0 \\
\hline ALMP_BEND & Comp** & 0 & 0 & 0 \\
\hline ALMP_EPL & 0 & Comp* & Comp* & Comp** \\
\hline EPL_TAX & 0 & 0 & 0 & 0 \\
\hline EPL_DENS & 0 & 0 & 0 & 0 \\
\hline EPL_BENF & 0 & 0 & 0 & 0 \\
\hline EPL_BEND & 0 & 0 & 0 & 0 \\
\hline TAX_DENS & 0 & 0 & 0 & 0 \\
\hline TAX_BENF & 0 & 0 & 0 & 0 \\
\hline TAX_BEND & 0 & 0 & Comp** & Comp*** \\
\hline DENS_BENF & 0 & 0 & 0 & 0 \\
\hline DENS_BEND & 0 & 0 & 0 & 0 \\
\hline BENF_BEND & 0 & 0 & 0 & 0 \\
\hline
\end{tabular}




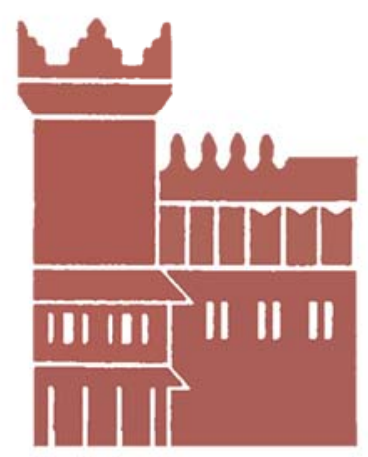

Alma Mater Studiorum - Università di Bologna DEPARTMENT OF ECONOMICS

Strada Maggiore 45

40125 Bologna - Italy

Tel. +39051 2092604

Fax +390512092664

http://www.dse.unibo.it 